@ERSpublications

This study shows that inhaled corticosteroids are not needed in COPD patients at low risk of exacerbations http://ow.ly/IkmDF

Andrea Rossi ${ }^{1}$, Thys van der Molen ${ }^{2}$, Ricardo del Olmo ${ }^{3}$ and Luis Wehbe ${ }^{4}$

${ }^{1}$ Pulmonary Unit, University of Verona, Verona, Italy. ${ }^{2}$ University Medical Center Groningen, University of Groningen, Groningen, The Netherlands. ${ }^{3}$ Fundación CIDEA and Hospital Maria Ferrer, Buenos Aires, Argentina. ${ }^{4}$ Fundacion Enfisema, Buenos Aires, Argentina.

Correspondence: Andrea Rossi, University and General Hospital Verona, Pulmonary Unit, Piazzale Stefani 1, Verona, 37126, Italy. E-mail: andrea.rossi_03@univr.it

Received: Jan 102015 | Accepted: Jan 122015

Conflict of interest: Disclosures can be found alongside the online version of this article at erj.ersjournals.com

\title{
References
}

1 Rossi A, van der Molen T, del Olmo R, et al. INSTEAD: a randomised switch trial of indacaterol versus salmeterol/fluticasone in moderate COPD. Eur Respir J 2014; 44: 1548-1556.

2 Global Initiative for Chronic Obstructive Lung Disease. Global Strategy for the Diagnosis, Management and Prevention of COPD. 2010. Available from: http://www.goldcopd.org/uploads/users/files/GOLDReport April112011.pdf Date last updated: April 11, 2011. Date last accessed: Oct 14.

3 Calverley PMA. What to use INSTEAD of inhaled corticosteroids in COPD? Eur Respir J 2014; 44: $1391-1393$.

4 Rossi A, Guerriero M, Corrado A, et al. Withdrawal of inhaled corticosteroid can be safe in COPD patients at low risk of exacerbation: a real-life study on the appropriateness of treatment in moderate COPD patients (OPTIMO). Respir Res 2014; 15: 77.

5 Agusti A, Fabri LM. Inhaled steroids in COPD: when should they be used? Lancet Respir Med 2014; 2: 869-871.

6 Lapperre TS, Snoeck-Stroband JB, Gosman MME, et al. Effect of fluticasone with and without salmeterol on pulmonary outcomes in chronic obstructive pulmonary disease: a randomized trial. Ann Int Med 2009; 151: 517-527.

7 Calverley PMA, Anderson JA, Celli B, et al. Salmeterol and fluticasone propionate and survival in chronic obstructive pulmonary disease. N Engl J Med 2007; 356: 775-789.

8 Suissa S. Number needed to treat in COPD: exacerbations versus pneumonias. Thorax 2013; 68: 540-543.

9 Wouters EFM, Postma DS, Fokkens B, et al. Withdrawal of fluticasone propionate from combined salmeterol/ fluticasone treatment in patients with COPD causes immediate and sustained disease deterioration: a randomised controlled trial. Thorax 2005; 60: 480-487.

10 Magnussen H, Disse B, Rodriguez-Roisin R, et al. Withdrawal of inhaled glucocorticoids and exacerbations of COPD. N Engl J Med 2014; 371: 1285-1294.

11 Hurst JR, Vestbo J, Anzueto A, et al. Susceptibility to exacerbation in chronic obstructive pulmonary disease. N Engl J Med 2010; 363: 1128-1138.

12 Fabbri LM, Romagnoli M, Corbetta L, et al. Differences in airway inflammation in patients with fixed airflow obstruction due to asthma or chronic obstructive pulmonary disease. Am J Respir Crit Med 2003; 167: 418-424.

13 Contoli M, Baraldo S, Marku B, et al. Fixed airflow obstruction due to asthma or chronic obstructive pulmonary disease: 5-year follow-up. J Allergy Clin Immunol 2010; 125: 830-837.

14 Corrado A, Rossi A. How far is real life from COPD therapy guidelines? An Italian observational study. Respir Med 2012; 106: 989-997.

\section{Sleep medicine certification for physicians in Spain}

To the Editor:

Sleep medicine is a rapidly growing field. At present, there is a lack of standardisation and the quality of clinical decisions may vary widely. The best way to resolve this problem is to establish a procedure for certification, for both centres and physicians [1]. However, the implementation of a procedure of this kind is difficult, for a variety of reasons; for example, the wide range of criteria applied by different professional societies and the apparent perception that sleep diseases belong to different medical specialties. To date, several procedures have been developed to perform the certification process. In some countries, for instance, the USA [1-3], sleep medicine is considered an independent medical subspecialty, and in Germany [4, 5] and Saudi Arabia [6], its status as a subspecialty has been officially acknowledged. In other 
countries, expertise is certified by scientific societies or academic institutions. The European Sleep Research Society started to certify sleep physicians in 2012 and it recently published its catalogue for sleep medicine certification $[7,8]$.

The understanding of sleep among specialists in fields such as psychiatry, ear, nose and throat (ENT) medicine, respiratory medicine, neurophysiology, neurology, and paediatrics tends to vary, and obviously all these experts need to share a common body of knowledge. Sleep medicine is a complex field requiring a considerable range of expertise, which a single physician is unlikely to possess. We think that the creation of interdisciplinary teams is the most promising approach: a similar language and a shared basic knowledge can facilitate a level of discussion between all the different specialists that is likely to lead to improvements in the practice of sleep medicine.

In our opinion, the process of certification should be the same for all the specialties inside sleep medicine in order to be able to ensure accurate clinical evaluation and to diagnose and treat the most common sleep entities, such as insomnia, snoring, sleep apnoea, ENT problems, restless leg syndrome, and "the basics" of other less frequent sleep diseases such as narcolepsy, rapid eye movement behaviour disorder, or other diseases that require mechanical ventilation. Certification would also improve the processes of referring rare diseases or the most complex cases of common diseases to the pertinent specialist $[3,9]$.

Here we describe the process of certification for physicians recently implemented in Spain. In common with other multispecialty certification systems and following (at least in part) the recommendations of the European Sleep Research Society guidelines [7, 8], this process was developed after an agreement between the main scientific medical societies involved in sleep medicine in Spain: the Respiratory Society (SEPAR), the Neurological Society (SEN), the Psychiatric Society, the ENT Society and the Sleep Society. The certification procedure is performed for a broad spectrum of sleep disorders and does not focus only on respiratory or paediatric sleep medicine. Physicians with $>10$ years' experience in sleep medicine are eligible to take the examination but the certification process has two general requirements. First, candidates must obtain 30 European credits for admission to the evaluation process and second, they must attend a 3-day course ( $12 \mathrm{~h}$ per day) on which the major sleep diseases and procedures are discussed. The course is divided into three parts: theoretical knowledge, case discussion and a practical hands-on session. Finally, candidates must pass an examination with both a theoretical and a practical section.

Some months before the course, participants receive a carefully selected list of recently reviewed papers on issues in sleep diseases and procedures. The distribution of the topics is approximately as follows: $12 \%$ physiology and pharmacology, 20\% evaluation, 30\% sleep-related respiratory diseases, 30\% sleep-related neurological and psychiatric diseases (insomnia, hypersomnias and sleep-related movement disorders), 5\% specific paediatric sleep diseases, and 3\% sleep in other medical disorders. We believe that the most important aspect of the evaluation process is the 3-day course in which physicians interact with their peers in a friendly, supportive environment, and which clearly helps to standardise patient management. A 30 -min lecture on each topic is followed by a general discussion that lasts for around $2 \mathrm{~h}$, coordinated by two specially appointed experts. The examination contains 40 theoretical questions concerning all areas of sleep medicine. Examples of these questions are: 1) the role of different neurotransmissions; 2) the characteristics of cannulas and thermistors; and 3) criteria for mechanical ventilation. The practical examination is in two parts: first, 10 questions on the typical traces of a full PSG; and then, the connection of a number of sensors for polysomnography or some mechanical ventilation settings.

The first course was held in May 2013 and was attended by physicians with $>10$ years practice and working either part-time or full-time in sleep medicine. 56 senior physicians working in sleep medicine in Spain attended the course and participated actively in the discussions. The level of satisfaction was high (with a mean satisfaction score of 18 out of 20) and all participants reported a significant improvement in their knowledge of sleep medicine. The participants considered that the most difficult questions were related to physiology and mechanical ventilation. In 2014, 50 out of 60 applicants were selected to take part in the course and the examination. In 2013 and 2014, a total of 105 candidates obtained certification, from the following medical specialties: 57 respiratory physicians, 35 clinical neurophysiologists, six neurologists, five ENT physicians, one psychiatrist and one internist.

Finally, the Spanish Health Authorities have recently created a specific competence area focussed on the recognition of new and emerging medical disciplines (e.g. neonatology). There is considerable backing for the inclusion of sleep medicine as a specific competence in the next updates of the law. The official recognition of sleep medicine as a subspecialty has the wide-ranging support of Spanish medical societies, as shown by their participation in the common certification process.

A further step would be to establish a similar certification process for sleep technologists and to develop educational opportunities for physicians who are not directly involved in sleep medicine. 
$@$ ERSpublications

There should be a procedure for certification of sleep centres and physicians http://ow.ly/HLGm3

Josep M. Montserrat ${ }^{1,2}$, Joaquin Terán-Santos ${ }^{1,2}$ and F. Javier Puertas ${ }^{1}$

${ }^{1}$ Spanish Committee of Sleep Medicine (CEAMS), Madrid, Spain. ${ }^{2}$ CIBERES, Madrid, Spain.

Correspondence: Josep M. Montserrat, Sleep Unit, Hospital Clinic, C/ Villarroel 170, Barcelona 08036, Spain. E-mail: jmmontserrat@ub.edu

Received: Oct 102014 | Accepted: Dec 052014

Conflict of interest: None declared.

\section{References}

1 Quan SF, Buysse DJ, Ward SL, et al. Development and growth of a large multispecialty certification examination: sleep medicine certification - results of the first three examinations. J Clin Sleep Med 2012; 8: 221-224.

2 American Board of Internal Medicine. Sleep medicine policies. www.abim.org/certification/policies/imss/sleep.aspx

3 Parthasarathy S, Haynes PL, Budhiraja R, et al. A national survey of the effect of sleep medicine specialists and American Academy of Sleep Medicine Accreditation on management of obstructive sleep apnea. J Clin Sleep Med 2006; 2: 133-142.

4 Deutschen Gesellschaft für Schlafforschung und Schlafmedizin. Qualifikationsnachweis Somnologie [Certification of qualification in somnology]. Somnologie 1997; 1: 97-100.

5 Penzel $\mathrm{T}$, Hein $\mathrm{H}$, Rasche $\mathrm{K}$, et al. Leitfaden für die Akkreditierung von schlafmedizinischen Zentren der Deutschen Gesellschaft für Schlafforschung und Schlafmedizin (DGSM) [Instructions for the accreditation of sleep centers of the German Sleep Society]. Somnologie 2000; 4: 181-187.

6 Bahammam AS, Al-Jahdali $\mathrm{H}$, Alharbi AS, et al. Saudi regulations for the accreditation of sleep medicine physicians and technologists. Ann Thorac Med 2013; 8: 3-7.

7 Penzel T, Pevernagie D, Dogas Z, et al. Catalogue of knowledge and skills for sleep medicine. J Sleep Res 2014; 23: 222-238.

8 Fischer J, Dogas Z, Bassetti CL, et al. Standard procedures for adults in accredited sleep medicine centres in Europe. J Sleep Res 2012; 21: 357-368.

9 Guerrero A, Embid C, Isetta V, et al. Management of sleep apnea without high pretest probability or with comorbidities by three nights of portable sleep monitoring. Sleep 2014; 37: 1363-1367.

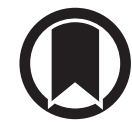

CrossMark

\section{Prevalence of Birt-Hogg-Dubé syndrome in patients with apparently primary spontaneous pneumothorax}

To the Editor:

Pneumothorax is classified "spontaneous pneumothorax" if there is no external force causing it and is classified as "primary spontaneous pneumothorax" (PSP) if there is no underlying lung disease. According to the guidelines of the British Thoracic Society (BTS), "no underlying lung disease" is based on history, physical examination and chest radiography [1].

Several years ago we evaluated the site of cystic lesions by thoracic computed tomography (CT) (slice thickness $10 \mathrm{~mm}$ ) in a group of 101 PSP patients. These lesions were described as blebs and bullae, and defined as air-containing thin-walled spaces in the pulmonary parenchyma [2]. The most common area found was subpleural in the upper lobes; however, in a minority (5\%), only small cystic lesions were found below the level of the main carina.

To confirm this finding in a more recent cohort, we reviewed the cohorts of PSP patients from a general and a university hospital. In 69 patients, CT had been performed within 1 year before or after the PSP and all CTs were scored on the presence of cyst(s) below the level of the carina. The mean age of the whole group was 37.6 years, the recurrence rate was $28.2 \%$ and a positive family history of spontaneous pneumothorax was noted in $16.2 \%$ of cases. In seven (10\%) patients, $>50 \%$ of the cysts were located below the level of the carina (table 1). 